\title{
O modelo constitucional de processo e o eixo estrutural da processualidade democrática.
}

\author{
The constitutional process model and the \\ structural axis of democratic processuality.
}

Leonardo Augusto Marinho Marques

Professor de Processo Penal da UFMG e da PUCMinas

Doutor em Ciências Penais pela UFMG

leonardo@leonardomarinho.com.br

Resumo: Neste artigo, analisar-se-á a relação entre Constituição e processo, a partir de teorias que surgiram na segunda metade do século XX. Passando pelo pensamento de Eduardo Couture, Héctor Fix-Zamudio, Elio Fazzalari e Italo Andolina e Giuseppe Vignera, apresentar-se-á o modelo constitucional de processo como referencial teórico que permite compreender o processo como garantia. No modelo constitucional, os princípios da não-parcialidade do juízo, contraditório, ampla argumentação e fundamentação da decisão se interligam, legitimando o ato jurisdicional que repercute na esfera de direitos dos cidadãos. Assim, pretende-se demonstrar que eixo estrutural da processualidade democrática é extraído desse núcleo principiológico.

Palavras-chave: Direito Processual. Constitucional. Processualidade democrática.

AвSTRACT: In this article we will analyze the relation between the Constitution and the process, in light of theories that have emerged in the second half of the twentieth century. Passing by the thought of Eduardo Couture, Héctor FixZamudio, Elio Fazzalari and Italo Andolina and Giuseppe Vignera, it will introduce the constitutional process model as a theoretical framework that allows us to understand the process as a guarantee. In the constitutional model, the principles of non-partiality of judgment, contradictory, extensive argumentation and decision motivation are interconnected, legitimizing the jurisdictional act that affects the citizens' rights sphere. Thus, we intend to demonstrate that the structural axis of democratic processuality is extracted from this core of principles.

KEYwoRds: Procedural law. Constitutional. Democratic processuality. 


\section{INTRODUÇÃo}

No artigo, analiso a relação entre Constituição e processo, a partir de teorias que surgiram na segunda metade do século XX. Passando pelo pensamento de Eduardo Couture, Héctor Fix-Zamudio, Elio Fazzalari e Italo Andolina e Giuseppe Vignera, apresento o modelo constitucional de processo como referencial teórico que permite compreender o processo como garantia.

Ressalto a necessidade de se superar a teoria da relação jurídica e o instrumentalismo processual, que justificaram o protagonismo judicial do século XX, elevando o juízo à condição de intérprete qualificado dos valores sociais e do sentimento geral de justiça de seu povo.

Examino os princípios processuais constantes no capítulo dos direitos fundamentais da Constituição de 1988, com o objetivo de encontrar as diretrizes impostas para o exercício da atividade processual. Parece-me, claro, que o ideal de construção comparticipada do ato decisório surge em afirmação ao pluralismo democrático.

No modelo constitucional, os princípios da não-parcialidade do juízo, contraditório, ampla argumentação e fundamentação da decisão se interligam, legitimando o ato jurisdicional que repercute na esfera de direitos dos cidadãos. Pretendo demonstrar que eixo estrutural da processualidade democrática é extraído desse núcleo principiológico.

\section{DA FUNDAMENTAÇÃo CONSTITUCIONAL DO PROCESSO AO MODELO CONSTITUCIONAL.}

A fundamentação constitucional do processo ganha evidência após a Segunda Grande Guerra Mundial, motivada por dois fatores: a inserção de diversas categorias processuais nas novas constituições e a assunção do controle de constitucionalidade, pelos juízes, ainda que de modo diferente em cada país (BARACHO, 2008: 25 e 323).

Nessa época, chega-se a pensar na existência de duas disciplinas, que teriam conteúdos distintos, embora idêntica fonte, que são as normas constitucionais. Alguns autores passaram a vincular o Direito Constitucional Processual ao Direito Constitucional e o Direito Processual 
Constitucional à teoria do processo (BARACHO, 2008: 323 e 348). A dualidade será superada com a consolidação do processo constitucionalizado.

Tendo como pressuposto a supremacia da Constituição sobre as normas processuais, Eduardo Couture e Héctor Fix-Zamudio enunciam o processo como instrumento de proteção de direitos fundamentais. (BARACHO, 2008: 11-13).

Coutoure e Zamudio deduzem o novo conceito das garantias, mas advertem que o processo constitucional não se realiza, no plano formal, com a positivação de princípios processuais. A efetividade do processo constitucionalizado dependerá da exata compreensão do conceito, extensão e limites dos preceitos constitucionais.

Lembre-se de que, desde o final do século XIX, a teoria do processo sofria forte influência do pensamento de Oskar von Bullow. Com a teoria da relação jurídica, o processo se configurou a partir dos vínculos subjetivos que se formam entre as partes e o juiz. Por conseqüência desses vínculos, um sujeito processual poderia exigir de outro a realização de um determinado comportamento.

$\mathrm{Na}$ relação jurídica, as partes aparecem em condição de desigualdade. Nela, o réu se sujeita à vontade do autor, devendo praticar a conduta por ele exigida. E, na relação jurídica, as duas partes ficam em desvantagem diante do juiz, representante do Estado, e detentor do poder de dizer o direito. $O$ papel de proeminência do julgador permite-lhe impor comportamentos às partes (GONÇALVES, 1992:70-74).

No marco teórico da relação jurídica, o processo constitui mero instrumento de jurisdição e a atividade decisória se legitima na consciência do julgador. A sua compreensão de vida, o modo como ele interpreta o fato e apreende os valores sociais são suficientes para the permitir adequar o direito à realidade que se lhe apresenta, independentemente da manifestação dos possíveis afetados. (LEAL, 2008: 25). Nessa perspectiva, a técnica processual não contempla a participação dos interessados, assim como a decisão judicial não passa pelo controle direto dos destinatários.

Somente na segunda metade do século XX, com o movimento de constitucionalização, é que a teoria do processo começa a abandonar a matriz da relação jurídica e a rever a instrumentalidade. A nova 
fundamentação constitucional tem reflexo imediato sobre a técnica processual. Os preceitos constitucionais reclamam a reestruturação do procedimento, visando a assegurar, para as partes, igual oportunidade, de intervenção influente, na atividade preparatória da decisão.

Elio Fazzalari presta enorme contribuição com sua teoria do processo como procedimento em contraditório (FAZZALARI, 2006). Primeiro, ele rompe com os vínculos de sujeição, próprios da relação jurídica, e lembra que, no Estado Democrático, somente o provimento estatal, proveniente de procedimento legítimo, pode impor condutas aos cidadãos. A vontade humana jamais poderá estabelecer, para outra pessoa, a obrigatoriedade de um comportamento.

Posteriormente, ele redefine procedimento, como atividade preparatória de um ato de poder, e processo, como espécie de procedimento, ou o procedimento realizado em contraditório entre as partes. Em Fazallari, o princípio constitucional do contraditório representa a garantia das partes de participação na formação do provimento, sempre em simétrica paridade. (GONÇALVES, 1992: 102-132)

Ampliando o horizonte fazzalariano do contraditório, Italo Andolina e Giuseppe Vignera concebem o modelo constitucional de processo, promovendo uma "aplicação mais dinâmica dos princípios constitucionais” (NUNES, 2009: 207). O processo começa a se estruturar em torno de uma "base principiológica uníssona"(BARROS, 2009a:334), presente na Constituição, que serve de orientação para a atividade processual. Essa base afirma a processualidade democrática, viabilizando a efetiva participação dos interessados e a tutela dos direitos fundamentais.

O modelo constitucional de processo é composto pelos princípios do contraditório, ampla argumentação, fundamentação da decisão e terceiro imparcial (BARROS, 2009b: 16).

Italo Andolina e Giuseppe Vignera conheciam a diferença entre as diversas espécies de processo, "seja em razão do provimento pretendido ou dos direitos fundamentais a serem garantidos" (BARROS, 2009b: 16), e tiveram o cuidado de construir um modelo bastante dinâmico, com capacidade de adequação a cada tipo de processo.

Nesse sentido, o núcleo de princípios formador do modelo constitucional de processo pode se expandir, aperfeiçoar-se e se especia- 
lizar, com o objetivo de se adaptar às especificidades dos microssistemas processuais, em face de suas características:

\begin{abstract}
"a expansividade, que garante a idoneidade para que a norma processual possa ser expandida para os microssistemas, desde que mantenha sua conformidade com o esquema geral de processo; a variabilidade, como a possibilidade de a norma processual especializar-se e assumir forma diversa em função da característica específica de um determinado microssistema, desde que em conformidade com base constitucional; e por fim a perfectibilidade, como a capacidade do modelo constitucional aperfeiçoar-se e definir novos institutos por meio do processo legislativo, mas sempre de acordo com o esquema geral" (BARROS, 2009b: p 15).
\end{abstract}

Destarte, no microcosmos do processo penal, por exemplo, a base principiológica precisa se expandir para absorver alguns princípios, como a presunção de não culpabilidade e o princípio acusatório, sob pena de não haver o aperfeiçoamento e a especialização mencionados anteriormente.

Preserva-se, assim, a idéia de um esquema geral extraído da Constituição, que permite conceber o processo como garantia, a partir da principiologia que lhe serve de referência, mas que, por suas próprias caraterísticas, ajusta-se à qualquer realidade processual.

\title{
2.1 O EIXO ESTRUTURAL DA PROCESSUALIDADE DEMOCRÁTICA:
} CO-RELAÇÃO ENTRE A NÃO-PARCIALIDADE DO JUÍZO, O CONTRADITÓRIO, A AMPLA ARGUMENTAÇÃO E A FUNDAMENTAÇÃO DA DECISÃO JUDICIAL.

Embora mantenha a expressão consagrada por Andolina e Vignera, modelo constitucional de processo, complementada pelos aportes teóricos recentes que lhe aprimoraram o conceito, proponho a substituição da expressão terceiro imparcial por não-parcialidade do juízo.

O conceito de imparcialidade exige nova leitura, diversa daquela concebida pela filosofia da consciência. Não há mais condição de se sustentar a imparcialidade a partir do distanciamento entre o sujeito cognoscente e objeto de conhecimento. Até porque, no século XX, a linguagem e a ciência romperam com os pressupostos daquela teoria: $\left(1^{\circ}\right)$ existe uma verdade pressuposta; (30) o sujeito é capaz de alcançá-la, 
sozinho, por meio da razão; $\left(2^{\circ}\right)$ para atingir a verdade, o sujeito deve se limitar a descrever a realidade, sem interagir com ela;

A suposta neutralidade defendida pela filosofia da consciência é ilusória. O homem é fruto de suas próprias contingências, nasce e é imerso em um contexto de linguagem, do qual não costuma se libertar. Inequivocamente, suas pré-compreensões permeiam o ato de interpretação.

Acredito que o ideal de imparcialidade deva ser substituído pelo conceito de não-parcialidade. Minha aposta é de que a não-parcialidade seja factível, e que possa ser construída objetivamente, tendo como referência critérios concretos. Esses critérios irão remeter ao debate e à crítica toda forma de pré-compreensão da vida e do direito.

Não-parcial, portanto, será quem aceitar o diálogo em torno do próprio ponto de vista. Será preciso, pois, abrir-se para o mundo e enxergar a diversidade; aceitar, com tranqüilidade, a possibilidade de que terceiros não compartilhem a mesma opinião; e, em certos momentos, propor-se a rever idéias.

Antecipando um pouco, o ideal de não-parcialidade não exigirá do juízo a compreensão do seu processo de formação subjetiva, nem tampouco o desvelamento de sua personalidade no processo. Os elementos da personalidade só podem ser trabalhados pela psicanálise, mesmo assim por iniciativa e vontade do interessado. Mas, há de se saber que o processo de auto-conhecimento é inesgotável.

No processo constitucional, definitivamente, não poderá haver patrulhamento sobre a sua visão de mundo. Quando muito, a não-parcialidade contribuirá para testificar as convicções pessoais do juízo no ambiente processual, propiciando condições para a construção compartilhada de uma realidade mais impessoal.

Pois bem, pretendo sustentar, com base no modelo constitucional de processo, que os princípios constitucionais da não-parcialidade do juízo, contraditório, ampla argumentação e fundamentação da decisão judicial, formam o eixo estrutural da processualidade democrática.

Entretanto, é preciso insistir: não há como buscar fundamentação constitucional para o processo sem abandonar a matriz da relação jurídica e a lógica da instrumentalidade. A conhecida técnica processual que confere primazia ao juízo na relação jurídica e transforma o proces- 
so em instrumento por meio do qual ele decide, solitariamente, conforme sua conviç̧ão pessoal, não se enquadra na realidade democrática.

$\mathrm{Na}$ democracia, não há espaço para argumentos qualificados, que se legitimam a priori, em razão da função ou do cargo que se exerce no Estado. O pluralismo democrático é incompatível com figura da autoridade, ou seja, o sujeito privilegiado que desenvolve sua percepção de forma solitária e sem conexão com o mundo da vida, para, em seguida, fundamentar o ato decisório na sua compreensão pessoal, sem diálogo e sem abertura para a diversidade.

No Estado Democrático, não há relação de hierarquia entre as instituições e os cidadãos. Há, ao contrário, igualdade jurídica, no nível "poliárquico". No plano da isonomia, Estado e cidadãos devem dialogar sobre matérias importantes. A democracia rompe, conscientemente, com o plano "autárquico-estatal", que confere primazia institucional no Estado Absoluto (LEAL, 2004: 49). Nessa nova realidade:

“as constituições não mais podem ser um estatuto totalizante e
exclusivo da atividade estatal, mas um texto articulador e legi-
timante das instituições jurídicas, em que o Estado comparece
como uma delas e com funções específicas, sem a conotação he-
geliana de expressão entitiva superior, criador de direitos, con-
dutor único e controlador normativo, soberano e absoluto da
sociedade política" (LEAL, 2004: 48).

Com efeito, a Constituição propôs um novo esquema processual, que assegura a construção participada do provimento. $\mathrm{O}$ processo democrático viabiliza a participação igualitária e influente dos interessados, conferindo-lhes ampla liberdade para interpretar o Direito, introduzir argumentos e produzir provas, no tempo do processo. Nesse quadro, classifico como inconstitucionais os pré-julgamentos e as decisões unilaterais.

A conexão entre os princípios da não-parcialidade do juízo, contraditório, ampla argumentação e fundamentação da decisão estabelece um novo eixo de racionalidade democrática para os provimentos judiciais, negando o "primado do juízo moralista sobre as provas e fatos do processo" (LOPES JÚNIOR, 2005:277) 
Antes, o juízo tinha liberdade de conviçção, mas obrigação de motivar a sua compreensão. Havia, ali, terreno fértil para ele desenvolver sua habilidade retórica e fundamentar sua interpretação pessoal, sempre à revelia da realidade objetiva construída, no processo, pelos argumentos e pelas provas. ${ }^{1}$

Ao juízo era permitido enxergar além e fazer prevalecer seu sentimento pessoal de justiça. Como a decisão não se vinculava, necessariamente, à realidade construída no processo, o controle de racionalidade da decisão se concentrava exclusivamente na fundamentação:

\begin{abstract}
“(...) com o objetivo de reduzir o máximo possível o componente pessoal e subjetivo no conhecimento judicial é que se afirma como regra constitucional fundamental o dever de motivação das decisões judiciais (art. 93, IX), para que se possam ser submetidas a um controle mínimo de racionalidade de sua fundamentação (...) as exigências de racionalidade jurídica das decisões judiciais apontam para a problematização acerca das motivações ou fundamentações dos julgados, e não da inevitável influência da subjetividade do julgador na escolha do referencial normativo para julgamento.”(OLIVEIRA, 2004: 172).
\end{abstract}

O problema é que, concentrando o controle do ato decisório exclusivamente na fundamentação, as partes ficam à mercê do juízo moral do julgador. Nessas condições, o dever de motivar cumpre o papel de legitimar as pré-compreensões do juízo, permitindo que a subjetividade se afirme sobre a realidade objetiva do processo.

Como o entendimento do juízo é exposto na sentença, sem que o processo the proporcione condição de verificação, as partes dependem do recurso para problematizá-lo. Consequentemente, o contraditório e a argumentação se retiram da etapa de formação do provimento, e deslocam-se para a instância revisora. Na primeira instância, o juízo continua soberano. E pode exercer sua atividade intelectiva com plena liberdade.

1 A jurisprudência brasileira consolidou o entendimento de que a decisão não precisa contemplar todos os argumentos das partes. A interpretação do juízo é autosuficiente, fundamentada na instrumentalidade e na teoria da relação jurídica. 
Com o modelo constitucional de processo, a situação se modifica substancialmente. A decisão não pode conter elementos novos, senão aqueles que foram introduzidos previamente no debate e que, por consequência, submeteram-se à discursividade processual, no tempo previamente demarcado. Nessa realidade, o ato decisório passa a ser controlado diretamente pelos destinatários.

Todavia, para se compreender a nova mentalidade, em toda sua dimensão, é preciso retomar aquela antiga preocupação de Couture e Zamudio em relação à efetivação do processo constitucional. $\mathrm{O}$ conceito e a extensão de cada princípio são fundamentais para a realização do processo constitucionalizado.

A não-parcialidade condiciona o convencimento do juízo ao debate e ao controle dos possíveis afetados. O "esforço argumentativo das partes" (BARROS, 2009b:21) e as provas produzidas judicialmente fazem com que a decisão se edifique em cima de uma realidade objetivada.

Sob o ângulo da democracia, trata-se de uma diretriz importante. Se o juiz não é o "único e valoroso intérprete do direito", a construção do provimento não comporta "discricionariedade e subjetivismo" (BARROS, 2009b:21). Historicamente, o dever de motivar a decisão não elidiu esses elementos antidemocráticos da fundamentação. Muitas vezes, a discricionariedade e o subjetivismo foram encobertos, na sentença, pelo silogismo e pela arte da retórica.

É preciso impedir que o sentire do juízo asfixie a argumentação jurídica e a atividade probatória. Para tanto, o contraditório deve ser compreendido como garantia de influência e não-surpresa, na perspectiva pós-fazzalariana. A ausência de co-relação entre o contraditório e a fundamentação da decisão acaba anulando a garantia de participação em simétrica paridade.

É necessário que o princípio do contraditório passe a expressar, para as partes, mais do que aquela garantia fazzalariana de participação isonômica no procedimento. Ele precisa alcançar a garantia de participação efetiva na preparação dos atos jurisdicionais. Com o novo conceito, a partes adquirem poder de influência sobre o conteúdo das decisões e o resultado do processo (NUNES, 2009: 226-227), evitando surpresa no provimento. 
O novo contraditório impede que o provimento jurisdicional inove com argumentos que não foram devidamente introduzidos naquela etapa procedimental que visa à preparação dos atos decisórios (garantia de não surpresa):

"Permite-se, assim, a todos os sujeitos potencialmente atingidos pela incidência do julgado (potencialidade ofensiva) a garantia de contribuir de forma crítica e construtiva para a sua formação" (NUNES, 2009: 227).

Vale a pena comentar que, na Europa, os atuais Códigos de Processo Civil, alemão, português, francês e austríaco já concebem o contraditório como garantia de influência e não-surpresa. No Brasil, é que ainda convivemos com o atraso. Não sedimentamos sequer o contraditório de Elio Fazzalari. Tem prevalecido, entre nós, o entendimento de que o contraditório é "a ciência bilateral dos atos e termos processuais e a possibilidade de contrariá-los”(ALMEIDA, 1973:82).

Sem dúvida, esse conceito possui enorme importância histórica, mas precisa ser atualizado. Com o passar do tempo, ele se tornou limitado e se revelou incapaz de absorver o ganho teórico proporcionado pela constitucionalização do processo.

Faz-se necessário aderir, com urgência, ao modelo constitucional de processo e compreender que o conteúdo do ato decisório provém da "comparticipação dos sujeitos do processo (juiz e partes contraditoras)” (DIAS, 2010:101).

O poder de influência sobre o conteúdo das decisões pode ser aferido pelos argumentos e provas que foram introduzidos no processo. Há de prevalecer a lógica de que o argumento provado deve ser recepcionado pela decisão e de que o argumento não provado deve ser rejeitado, salvo se houver dúvida razoável em favor do acusado. São eles que formam a realidade objetiva e edificante da decisão, e que excluem os juízos morais, subjetivos e unilaterais.

A garantia de ampla argumentação é estendida a todos os possíveis afetados pelos efeitos do provimento. Cada um deles tem igual direito de interpretar o Direito e de sustentar argumentos que tenham o potencial de interferir na compreensão da realidade. Suas 
interpretações têm lugar cativo no ambiente processual e passam a condicionar a fundamentação. Em suma, o processo cumpre a função de institucionalizar os discursos, demarcando o tempo inerente ao diálogo democrático.

Percebam que não proponho o fim da atividade interpretativa do juízo, nem concordo que ele seja apenas um expectador do trabalho das partes. O Juízo não deve se limitar a acolher um dos discursos propostos, sem dele poder divergir. Ele pode se inserir no debate, problematizar a realidade e interagir com a prova proposta pelas partes. Posiciono-me contrário, apenas, à proposição de provas pelo juízo. Esta é uma prerrogativa das partes, sobretudo no processo penal.

No modelo constitucional de processo, o juízo precisa conhecer todos os argumentos e entender que a prova fixa fatos. A realidade que se firma diante de seus olhos interfere na decantada liberdade de convencimento. Seu alcance não é absoluto. O primado da hipótese cede passagem à institucionalização dos discursos. Alimentase, assim, o ideal de construção de uma decisão menos impessoal. (BARROS, 2009b:21)

Inevitavelmente, a não-parcialidade, o contraditório e a ampla argumentação estabelecem uma relação de co-dependência com a fundamentação. Antes, o direito havia sido reduzido a uma construção individual, "monológica e prospectiva" (GALUPPO, 2001:57-58). Essa construção individual provinha de "um estado de natureza hermenêutico, no interior do qual o juiz decide como mais lhe aprouver" (STRECK, 2009:6).

Com o processo constitucional, o direito se transforma no resultado de uma interpretação plural e dialógica, obtida a partir de uma realidade problematizada pelas partes e pelo juízo.

Se a principiologia constitucional exige que o ato decisório seja construído no processo, de forma compartilhada, a fundamentação precisa espelhar a argumentação jurídica empreendida pelas partes, e mostrar, por meio da prova produzida, por que a decisão enuncia a resposta adequada, diante de pontos de vista opostos.

A processualidade democrática lança a realidade objetiva do processo contra o subjetivismo e discricionariedade do juízo. 


\section{ConCLUSÃo}

A constitucionalização do processo reclama a superação da teoria da relação jurídica e da instrumentalidade processual. O modelo constitucional de processo recomenda a aplicação dinâmica de princípios que viabilizam comparticipação dos sujeitos processuais na atividade preparatória do provimento.

Depreende-se, pois, desse núcleo principiológico o eixo estrutural da processualidade democrática. Os princípios da não parcialidade do juízo, contraditório, ampla argumentação e fundamentação da decisão se conectam para legitimar o ato decisório. Este somente repercutirá, legitimamente, na esfera de direitos dos cidadãos, se precedido pelo debate e se amparado na prova produzida.

Enfim o juízo não pode se convencer daquilo que não foi debatido e nem do que não restou provado.

\section{REFERÊNCIAS}

ALMEIDA, Joaquim Canuto Mendes de. Princípios Fundamentais do Processo Penal. São Paulo: Revista dos Tribunais, 1973

BARACHO, José Alfredo de Oliveira. Direito processual constitucional: aspectos contemporâneos. Belo Horizonte: Fórum, 2008.

BARROS, Flaviane Magalhães de Barros. Modelo constitucional de processo e o processo penal: a necessidade de uma interpretação das reformas do processo penal a partir da Constituição. In: MACHADO, Felipe Daniel Amorim. OLIVEIRA, Marcelo Andrade Cattoni de (coord). Constituição e processo: A contribuição do processo ao constitucionalismo democrático brasileiro. Belo Horizonte: Del Rey, 2009a.

BARROS, Flaviane Magalhães de Barros. (Re) forma do processo penal: comentários críticos dos artigos modificados pelas Leis n. 11.690/08, $n .11 .719 / 08$ e n. 11.900/08. 2a ed.. Belo Horizonte: Del Rey, 2009b.

DIAS, Ronaldo Bretas de Carvalho. Processo constitucional e Estado Democrático de Direito. Belo Horizonte: Del Rey, 2010. 
FAZZALARI, Elio. Instituições de Direito Processual. Tradução de Elaine Nassif. Campinas: Bookseller, 2006.

GALUPPO, Marcelo Campos. Hermenêutica e jurisdição constitucional. In: SAMPAIO, José Adércio Leite. CRUZ, Álvaro Ricardo de Sousa (coord.). Hermenêutica e jurisdição constitucional. Belo Horizonte: Del Rey, 2001.

GONÇALVES, Aroldo Plínio. Técnica Processual e Teoria do Processo. Rio de Janeiro: Ed. Aide, 1992.

LEAL, André Cordeiro. Instrumentalidade do processo em crise. Belo Horizonte: Mandamentos, Faculdade de Ciências Humanas/FUMEC, 2008.

LEAL, Rosemiro Pereira. Teoria geral do processo: primeiros estudos. $5^{\mathrm{a}}$ ed. São Paulo: Thomson-IOB, 2004.

LOPES JUNIOR, Aury. Introdução crítica ao processo: fundamentos da instrumentalidade garantista. 3. ed. Rio de Janeiro, Lumen Juris: 2005.

OLIVEIRA, Eugênio Pacelli. Processo e hermenêutica na tutela dos direitos fundamentais. Belo Horizonte: Del Rey, 2004.

NUNES, Dierle José Coelho. Processo jurisdicional democrático: uma análise critica das reformas processuais. Curitiba: Juruá, 2009.

STRECK, Lênio Luiz. Hermenêutica, Constituição e Processo, ou de "como a discricionariedade não combina com democracia: o contraponto da resposta correta. In: MACHADO, Felipe Daniel Amorim. OLIVEIRA, Marcelo Andrade Cattoni de (coord). Constituição e processo: A contribuição do processo ao constitucionalismo democrático brasileiro. Belo Horizonte: Del Rey, 2009a.

\section{COMO CITAR ESTE ARTIGO:}

MARQUES, Leonardo Augusto Marinho. O modelo constitucional de processo e o eixo estrutural da processualidade democrática. Revista Brasileira de Direito Processual Penal, Porto Alegre, vol. 2, n. 1, p. 43 - 55, 2016. http://dx.doi.org/10.22197/rbdpp.v2i1.16 